\begin{tabular}{|c|c|}
\hline$\beth$ & $\begin{array}{c}\text { International Journal of Current Research } \\
\text { and Academic Review }\end{array}$ \\
\hline $\begin{array}{l}\text { XCELLENT } \\
\text { JBLISHERS }\end{array}$ & $\begin{array}{r}\text { ISSN: 2347-3215 (Online) ,; Volume s, ; N } \\
\text { Journal homepage: http://www.ijer }\end{array}$ \\
\hline
\end{tabular}

doi: https://doi.org/10.20546/ijcrar.2017.504.016

\title{
Lipases in Environmental Management
}

\author{
Pallavi Pogaku*, P. Bhavani, T. Manjusha and K. Saritha \\ Department of Microbiology, Govt. Degree College for Women, Nalgonda, Telangana state, India \\ *Corresponding author
}

\begin{abstract}
Extra cellular lipase producing bacteria were isolated from different oil mill soils and screened on tributyrin and spirit blue agar medium. Lipases have become an integral part of the modern food industry. The use of enzymes to improve the traditional chemical processes of food manufacture. Lipases have been used for the degradation of wastewater contaminants such as olive oil from oil mills. The microbial treatment of waste from fast-food restaurants for the removal of fats, oils and greases. They cultivated pure and mixed microbial flora known to produce lipases and other enzymes. Acinetobacter $s p$. was the most effective of the pure cultures, typically degrading $60-65 \%$ of the fatty material.
\end{abstract}

\section{Article Info}

Accepted: 08 April 2017

Available Online: 20 April 2017

\section{Keywords}

Lipase, tributyrin agar,

Microbial treatment,

food industry.

\section{Introduction}

The annual market for industrial enzymes has reached around US $\$ 1.6$ billion in 2000. Twelve major suppliers and four hundred minor producers assure the world demand of enzymes. Europe alone produces around $60 \%$ of the total world supply of industrial enzymes which are mainly (at least $75 \%$ ) hydrolytic including proteases, carbohydrases and lipases (Sharma et al., 2001). Lipases (triacylglycerol acylhydrolase, EC 3.1. 1.3) are part of the family of hydrolases that act on carboxylic ester bonds. Their physiological role is to hydrolyze triglycerides to diglycerides monoglycerides, fatty acids and glycerol. Lipase producing bacteria were reported nearly one century ago by the microbiologist, (Jaeger and Eggert, 2002) but it is not until the 1950s that the first works on fungal lipases were reported (Ghosh et al., 1996). Lipases catalyze esterification, interesterification, acidolysis, alcoholysis and aminolysis in addition to the hydrolytic activity on triglycerides. As hydrolases, they do not require cofactors. They usually exhibit good chemioselectivity, regioselectivity and enantioselectivity. Finally, lipases possess broad substrate specificity and can be found with optimum activities over a wide range of temperatures. These interesting properties make lipases the most versatile biocatalyst. Their applications are found in the detergent, food, leather, textile, oil and fat, cosmetic, paper and pharmaceutical industries (Kademi et al., 2004). Commercial use of lipases in various applications is a billion-dollar business. In the detergent industry, about 1000 tons of lipases are sold every year (Godfrey and West, 1996).

\section{Distribution of lipase producers}

Production of lipases by a variety of bacteria, fungi and actinomycetes has been reported. The presence of lipases in bacteria had been observed as early as 1901 A.D. for Bacillus prodigiosus, Bacillus pyocyneus, and Bacillus fluorescens which represent some of today's best studied 
lipase producers, now named, Serratia marcescens, Pseudomonas aeruginosa and Pseudomonas fluorescens respectively. Lipase producers have been isolated mainly from soil or spoiled food material that contains vegetable oils. Lipases also represent important virulence factor of many plant and animal pathogens. Lipases with novel properties have been discovered from microorganisms isolated from antarctic ocean, hot springs, compost heaps and highly salty or sugary environments. Lipase producers have been reported to grow at varied $\mathrm{pH}$ and temperatures. The fungi are usually reported to require acidic $\mathrm{pH}$ for growth and lipase production. Many bacteria are found to prefer neutral $\mathrm{pH}$ but there are reports of alkalophilic bacteria. Psychrophilic and thermophilic organisms, as well as organisms having different oxygen demand (aerobic, microaerophilic and anaerobic) are reported to produce lipases.

\section{Production of lipases}

Bacterial lipases are mostly inducible enzymes, requiring some form of oil, fatty acid, fatty acid alcohol or fatty acid ester for induction. However, there are a few reports of constitutive lipase production by bacteria (Gao et al., 2000). Lipases are usually secreted out in the culture medium; although there are a few reports of the presence of intracellular lipases as well as cell bound lipases (Large et al., 1999). The onset of lipase production is organism-specific, but, in general, it is released during late logarithmic or stationary phases.

\section{Commercial applications of lipases}

Lipases possess the unique feature of acting at an interface between the aqueous and nonaqueous (i.e. organic) phase; this feature distinguishes them from esterases. Lipase activity generally depends on the available surface area. Lipases are the most versatile biocatalysts and they bring about a range of bioconversion reactions such as hydrolysis, interesterification, esterification, alcoholysis, acidolysis and aminolysis. Lipases act under extremely mild conditions (Sharon et al., 1999). They can be used in a variety of organic solvents and often show selectivity for a specific reaction type.

Lipases are an excellent alternative to many classical organic techniques in the selective transformation of complex molecules. They possess many features that favor their use as an excellent biocatalyst. They impart specificity to a reaction, in which a chemical process is typically more non-specific. In addition, the use of enzyme can decrease side reactions and simplify postreaction separation problems (Pandey et al., 1999). Lipase-catalyzed processes are reported to offer costeffectiveness too, in comparison with traditional downstream processing in which energy consumption and toxic by-products might often pose problem. The alkaline thermophilic lipases find application in detergent industry Many fatty food stains and human serum contain triglycerides which are hydrolyzed by lipases to produce fatty acids, monoglycerides and diglyceries, which are easier to remove than unhydrolyzed triglycerides (Fuji et al., 1986).

\section{Lipases in food industry}

Lipases have become an integral part of the modern food industry. The use of enzymes to improve the traditional chemical processes of food manufacture has been developed in the past few years. Yoneda et al., (1996) have patented a process on Pseudomonas lipase, which was claimed to be useful in, for example, food processing and oil manufacture. Alcoholysis of cod liver oil for the production of omega- 3 polyunsaturated fatty acids was investigated by using Pseudomonas lipase (Zuyi and Ward, 1993). A few bacteria produce flavour esters and find use in cheese industry. The production of flavour esters by lipases of Staphylococcus warneri and Staphylococcus xylosus has also been described by Talon et al., (1996). Synthesis of fatty acid esters by a recombinant Staphylococcus epidermidis lipase has been described by Chang et al., (2001). Chromobacterium viscosum lipase was shown to have good potential for the instant generation of aroma and flavour compounds and could be stored at least for one month. In this case, the lipase activity was immediately regenerated on dehydration.

\section{Lipases in biomedical application}

Because of their excellent capability for specific regioselective reactions in a variety of organic solvents with broad substrate recognition, lipases have emerged as an important biocatalyst in biomedical applications. Recently, Parmar et al., (1996) have reviewed a variety of substrates accepted by hydrolytic enzymes, including lipases, to produce compounds in high enantiomeric excess, which can be used as chiral building blocks for the synthesis of compounds of pharmaceutical interest. Conventional chemical synthesis of drugs containing a chiral center generally yields equal mixtures of enantiomers. During the past decade, many studies have shown that racemic drugs 
usually have the desired therapeutic activity residing mainly in one of the enantiomers and the other enantiomer might interact with different receptor sites, which can cause unwanted side effects (Pandey et al., 1999).

\section{Lipases in pesticides}

A variety of pesticides (insecticides, herbicides, fungicides or their precursors) made with the applications of lipases are currently in the use (Pandey et al., 1999). The most important application of lipases has been in the organic synthesis of pesticides for the production of optically active compound (Reddy, 1992). Generally, these compounds were produced through the resolution of racemic mixtures of alcohol or carboxylic esters; stereospecific synthesis reactions were also employed. A highly stereospecific synthesis of the versatile chiral synthon possessing two stereogenic centres, which was subsequently converted into a homochiral intermediate for the synthesis of the biologically active potent pesticide nikkomycin-B. Use of Achromobacter lipase for enantioselective hydrolysis of the acetic acid ester of racemic a-cyano-3-phenoxybenzyl alcohol (CPBA) for the production of (S)-CPBA, an active insecticidal stereoisomer.

\section{Lipases as detergents}

Lipases were generally added to the detergents primarily in combination with proteases and cellulases. However, other enzymes such as amylases, peroxidases and oxidases are also reported to be added in detergent preparations. Removal of oil/fatty deposits by lipase is attractive owing to its suitability under milder washing conditions. To be a suitable additive in detergents, lipases should be both thermostable as well as alkalophilic and capable of functioning in the presence of the various components of washing powder formulations (Jaeger et al., 1994).

Pseudomonas lipase preparations have been used for preparation of washing powder formulations. Pseudomonas medocina (Lumafast*) and Pseudomonas alcaligenes (Lipomax*) lipases have been manufactured by Genencor international USA, as detergent additive (Jaeger, 1998). The Novo group has reported a highly alkaline, positionally non-specific lipase, from a strain of Streptomyces sp. that was useful in laundry and dishwashing detergents as well as industrial cleaners (Pandey et al., 1999).

\section{Lipases in the leather industry}

Leather processing involves the removal of subcutaneous fat, de-hairing and stuffing. Tanning processes are usually performed in an alkaline environment, so alkalophilic microbes ought to be better for exploration. Many Bacillus sp. strains, which grew successfully under highly alkaline conditions, were found to be useful in leather processing (Haalck et al., 1992).

\section{Lipases in environmental management}

Lipases have been used for the degradation of wastewater contaminants such as olive oil from oil mills (Vitolo et al., 1998). The treatment process involved the cultivation of lipase-producing microbial strains in the effluents. The microbial treatment of waste from fastfood restaurants for the removal of fats, oils and greases. They cultivated pure and mixed microbial flora known to produce lipases and other enzymes. Acinetobacter sp. was the most effective of the pure cultures, typically degrading $60-65 \%$ of the fatty material.

\section{Conclusions}

The development of enzymes with novel properties by exploring the present biological diversity or by creating newer enzyme variants plays a pivotal role in future enzyme technology. Microorganisms constitute the potential source of enzymes due to their broad biochemical diversity, feasibility of mass culture and ease of genetic manipulation. Microbial enzymes find a variety of industrial applications. Extracellular enzymes from microbial sources generally meet industrial demands due to their potential applications in various fields. The screening programs for the isolation of enzyme producing microorganisms from soil represents the most common source as they are present in diverse habitats and may provide novel isolates or high yielding strains, which can be exploited for industrial purposes. Microbial lipases (EC 3.1.1.3) fall in the category of bulk selling industrial enzymes which find wide applications in the textile and detergent industries and also find specific applications in the food and pharmaceutical industries.

Till date, a variety of microorganisms that are capable of producing lipases have been isolated. The significant progress has been achieved in purification, characterization of different lipases and in understanding their substrate specificities and their mode of action. 
Microbial lipases are generally active in acidic to neutral $\mathrm{pH}$ range. Recently, enzymes that are active and stable in neutral to alkaline conditions have gained significant commercial importance due to their eco-friendly applications in detergent, textile, leather and pharmaceutical and agro industries. Of lipases, bacterial lipases are considered to be important as they have a variety of industrial applications. During the past decade, many bacterial lipases have been purified and characterized. Because of the need of lipases with high specific activity at alkaline $\mathrm{pH}$ and temperature, which are critical parameters to be used in detergent and food industries, alkaliphilic, thermostable lipolytic enzymes are receiving considerable industrial importance.

\section{References}

Chang, R.C., Chou, S.J. and Shaw, J.F. 2001. Synthesis of fatty acid esters by recombinant Staphylococcus epidermidis lipases in aqueous environment. $J$. Agric. Food Chem., 49(5): 2619-2622.

Fuji, T., Tatara, T. and Minagwa, M. 1986. Studies on application of lipolytic enzyme in detergency I. $J$. Am. Oil Chem. Soc., 63(6): 796-799.

Gao, X.G., Cao, S.G. and Zhang, K.C. 2000. Production, properties and application to nonaqueous catalysis of lipase from a newly isolated Pseudomonas strain. Enzym. Microb. Technol., 27: 74-82.

Ghosh, P.K., Saxena, T.K., Gupta, R., Yadav, R.P. and Davidson, S. 1996. Microbial lipases: Production and applications. Sci. Prog., 79: 119-157.

Godfrey, T. and West, S. eds. 1996. Industrial Enzymology. The application of Enzymes in Industry, New York, Stockton Press.

Haalck, L., Hedrich, H.C., Hassink, J. and Spener, F. 1992. Modification of waste fats by lipase-catalyzed reaction in solvent-free substrate blends. Prog. Biotechnol., 8: 505-512.

Jaeger, K.E. and Eggert, T. 2002. Lipases for biotechnology. Curr. Opin. Biotechnol., 13(4): 390397.

Jaeger, K.E., Ransac, S., Dijkstra, B., Colson, C., Heuvel, M. and Misset, O. 1994. Bacterial lipases. FEMS Microbiol. Rev., 15: 29-63.
Kademi, A., Lee, B. and Houde, A. 2004. Microbial Enzymes; Production and Applications: Lipase, InConcise Encylopedia of Bioresource Technology, Pandey A. ed), Haworth Press, Binghamton, NY, USA: 433-442.

Large, K.P., Mirjalili, N., Peacock, M.O.L.M., Zormpaidis, V., Walsh, M., Cavanagh, M.E., Leadlay, P.F. and Ison, A.P. 1999. Lipase activity in Streptomycetes. Enzym. Microb. Technol., 25(7): 569-575.

Lawler, D. and Smith, S. 2000. Enzyme producing strain of Bacillus bacteria. Roebic Laboratories, Inc., USA) U. S. US 6162634 A. CA 134: 41190.

Pandey, A., Benjamin, S., Soccol, C.R., Nigam, P., Krieger, N. and Soccol, V.T. 1999. The realm of microbial lipases in biotechnology. Biotechnol. Appl. Biochem., 29: 119 -131.

Parmar, V.S., Bisht, K.S., Singh, A. and Jha, A. 1996. Potentially useful lipase catalyzed transesterifications. Proc. Ind. Acad. Sci., 108: 575583.

Reddy, D.R. 1992. In: Industrial Biotechnol. edited by Malik V. S. and Sridhar P., 387-404, Oxford and IBH Publishing Co., New Delhi.

Sharma, R., Chisti, Y. and Banerjee, U.C. 2001. Production, purification, characterization and applications of lipases. Biotechnol Adv., 19: 627662.

Sharon, C., Nakazato, M., Ogawa, H.I. and Kato, Y. 1999. Bioreactor operated production of lipase: Castor oil hydrolysis using partially purified lipase. Ind. J. Exp. Biol., 37: 481-486.

Talon, R., Montel, M.C. and Berdague, J.L. 1996. Production of flavor esters by lipases of Staphylococcus warneri and Staphylococcus xylosus. Enzym. Microb. Technol., 19(8): 620-622.

Vitolo, S., Petarca, L. and Bresci, B. 1998. Treatment of olive oil industry wastes. Biores. Technol., 67: 129137.

Yoneda, T., Takada, H., Ohno, K. and Sasuga, J. 1996. Cloning of gene for novel lipase of Pseudomonas, recombinant production of lipase, and its uses, Pat. WO 9627002. CA 125: 269257.

Zuyi, L. and Ward, O.P. 1993. Stability of microbial lipase in alcoholysis of fish oil during repeated enzyme use. Biotechnol. Lett., 15: 393-398.

\section{How to cite this article:}

Pallavi Pogaku, P. Bhavani, T. Manjusha and Saritha, K. 2017. Lipases in Environmental Management. Int.J.Curr.Res.Aca.Rev. 5(4), 106-109. doi: https://doi.org/10.20546/ijcrar.2017.504.016 